\title{
LAS NEGOCIACIONES INCOMPATIBLES COMO CAUSAL DE DESPIDO EN CHILE
}

\author{
INCOMPATIBLE NEGOTIATIONS AS A CAUSE OF \\ DISMISSAL IN CHILE
}

ÁLVARO DOMÍNGUEZ MONTOYA*

\section{RESUMEN}

La presente investigación se propone generar un estudio sistemático y crítico del artículo 160 número 2 del Código del Trabajo, que contribuya a detectar, especificar y superar los problemas que presenta el desarrollo dogmático de las negociaciones incompatibles como causal de despido en el ordenamiento jurídico chileno. En este esquema, definimos la hipótesis de despido disciplinario como una forma de no concurrencia relativa o parcial que, en su estructura tipológica, responde a un ilícito de mera actividad, configurado por la abstención de ejecución de actividades mercantiles o civiles por cuenta propia, autónomas o de carácter asociativo, que se encuentren dentro del giro del empleador y no así actividades laborales o subordinadas, siempre y cuando estén expresamente prohibidas por escrito.

Palabras clave: Sanción laboral, Poder disciplinario, Despido, Negociaciones incompatibles, Competencia desleal, Libertad de trabajo.

\footnotetext{
*Abogado, Licenciado en Ciencias Jurídicas y Sociales por la Universidad de Concepción (Chile). Máster en drets sociolaborals y doctor en Derecho por la Universitat Autònoma de Barcelona (Catalunya). Profesor instructor en el Departamento de Derecho Laboral, Facultad de Ciencias Jurídicas y Sociales, Universidad de Concepción, Concepción, Chile. Correo electrónico: adominguez@udec.cl. Código Orcid: https://orcid.org/0000-0001-9059-6730

Artículo recibido para evaluación el 26 de abril de 2020, y aprobado para su publicación el 19 de noviembre de 2020 .
} 


\section{ABSTRACT}

This research aims to generate a systematic and critical study of article 160 number 2 of the Labor Code which helps to detect, specify and overcome the problems presented by the dogmatic development of incompatible negotiations as grounds for dismissal in the Chilean legal system. In this scheme, we define this hypothesis of disciplinary dismissal as a hypothesis of relative or partial non-concurrence that, in its typological structure, responds to an illicit act of mere activity, configured by the abstention from the execution of commercial or civil activities on own account, autonomous or associative in nature, which are within the employer's line of business and not work or subordinate activities, as long as these, by law, are prohibited activities that are outside the company's line of business and that are expressly prohibited in writing.

Keywords: Labor penalty, disciplinary power, dismissal, incompatible negotiations, unfair competition, freedom of work.

\section{INTRODUCCIÓN}

Esta investigación se centra en el estudio de la causal de despido disciplinario de negociaciones incompatibles, contemplada en el artículo 160 número 2 del Código del Trabajo.

En este contexto, el objetivo principal es generar un estudio sistemático y crítico que contribuya a detectar, especificar y superar los problemas que presenta el desarrollo de esta causal desde una perspectiva que otorga centralidad valórica al trabajo en nuestro modelo jurídico, social y político.

En cuanto a sus objetivos específicos, en primer lugar, se pretende dilucidar los alcances de la causal de despido a través de la identificación y el análisis de sus rasgos fundamentales. En segundo lugar, efectuar una propuesta teórica para analizar sus aspectos sustantivos de manera unitaria y coherente. En tercer lugar, y desde un análisis crítico, servir de fundamento para cuestionar su desarrollo y evolución en la doctrina chilena.

La metodología utilizada para abordar el objetivo principal y los objetivos específicos de esta investigación consistió en un estudio analítico 
y sistemático de fuentes normativas y doctrinarias. ${ }^{1}$

En este esquema, el perfil adoptado fue el de una investigación "sistematizadora" y de "lege data", 3 al reunir componentes descriptivos y prescriptivos que, desde una perspectiva crítica y un enfoque tipológico, exponen los aspectos generales, características y fundamentos que identifican teóricamente la dogmática de la causal de despido en estudio, buscando develar el conjunto de los elementos esenciales que modelan tal institución, sus problemáticas y respuestas.

Respecto de la jurisprudencia citada, su estudio no pretende ser exhaustivo, ya que el enfoque del artículo es esencialmente doctrinario, por lo que se utilizó una muestra intencional ${ }^{4}$ de sentencias paradigmáticas y de relevancia que nos parecieron más idóneas para los objetivos de esta investigación, ${ }^{5}$ centrándose en un análisis de contenido cualitativo de texto. ${ }^{6}$

\section{NOCIONES GENERALES DE LAS NEGOCIACIONES INCOMPATI- BLES COMO CAUSAL EXTINTIVA}

\section{Contexto histórico normativo}

Desde un punto de vista normativo, nuestra legislación social solo hace referencia a la concurrencia laboral o competencia desleal ${ }^{7}$ mientras el contrato de trabajo se encuentre vigente, regulando expresamente su

\footnotetext{
${ }^{1}$ Se identificó, recopiló y estudió en integridad la bibliografía del derecho chileno sobre la causal de estudio, tomando como referencia y de manera reflexiva, las problemáticas y respuestas dadas por la doctrina española a los principales nudos críticos a nuestro modelo de despido disciplinario, por las influencias idiomáticas y culturales del derecho español laboral en la doctrina nacional.

${ }^{2}$ Courtis, Christian, "El juego de los juristas. Ensayo de caracterización de la investigación dogmática", en: Courtis, C., Observar la ley. Ensayos sobre metodología de la investigación jurídica, Editorial Trotta, Madrid, 2006, p. 118.

${ }^{3}$ Courtis, cit. (2), p. 122.

${ }^{4}$ VERD, Joan; LozARES, Carlos, Introducción a la investigación cualitativa. Fases, métodos y técnicas, Síntesis, Madrid, 2006, pp. 113-155.

${ }^{5}$ Ruzz, José, Metodología de la investigación cualitativa, Universidad de Deusto, Bilbao, 2012, pp. $62-65$.

${ }^{6}$ Verd y LozAREs, cit. (n. 4), pp. 305-309.

${ }^{7}$ Existen una serie de distinciones semánticas con respecto a la idea de no concurrencia, no competencia y competencia desleal, entre otras expresiones, como concepto unitario. Sobre el punto, ver CASTIÑEIRA, Jaime, Prohibición de competencia y contrato de trabajo, Ministerio del Trabajo y Seguridad Social, Madrid, 1977, pp. 115 y ss.
} 
infracción como una hipótesis de despido subjetivo. ${ }^{8}$

En nuestro ordenamiento, la recepción de la regulación de no competencia laboral se produjo con las primeras leyes sociales, para luego incorporarse en el Código del Trabajo de 1931 haciendo referencia a la extinción disciplinaria del contrato de trabajo de los empleados, lo que posteriormente se extendería al resto de los trabajadores con la unificación de categorías y estamentos laborales con la Ley 16.455, manteniendo su redacción hasta nuestros días. ${ }^{9}$

Actualmente, esta causal extintiva está regulada en el artículo 160 número 2 del Código del Trabajo, que preceptúa que el contrato de trabajo termina sin derecho a indemnización por las "negociaciones que ejecute el trabajador dentro del giro del negocio y que hubieren sido prohibidas por escrito en el respectivo contrato por el empleador".

Ahora, desde un punto de vista histórico y general, los antecedentes normativos de esta causal son reconducidos a la legislación mercantil, en particular a la regulación del trabajo de factores y dependientes de comercio, la que por efecto expansivo alcanzó otros órdenes regulatorios, entre estos, el laboral. ${ }^{10}$

La expansión y derivación de estas pautas normativas tienen relación con que la regulación comercial y civil fueron antecesoras de la legislación social, produciéndose una "paulatina atracción de las prestaciones mercantiles hacia el ordenamiento jurídico laboral" que terminaría por absorberlas en su racionalidad, imponiendo sus condiciones de trabajo características, entre ellas la prohibición de competencia. ${ }^{11}$

En este contexto, como factor común normativo histórico, en los albores del derecho del trabajo, la regulación mercantil, si bien en principio era propia de una sociedad "preindustrial" y "paleocapitalista" de empresas de reducida dimensión, admitía la plena licitud de todas las conductas externas al trabajo que no incidieran negativamente con la propia prestación,

\footnotetext{
${ }^{8}$ Sierra, Alfredo, "La cláusula de no competencia post-contractual en el contrato de trabajo", Ius et Praxis, 2014, N², pp. 110 y ss.

${ }^{9}$ IruREta, Pedro, "La prohibición de competencia y buena fe contractual”, Estudios Laborales, 2007, v.I, pp. 54 y 55.

${ }^{10}$ En Chile: IrURETA, cit. (n. 9), pp. 52 y ss. En el ordenamiento jurídico español, entre otros: Nogueira, Magdalena, La prohibición de competencia desleal en el contrato de Trabajo, Editorial Aranzadi, Pamplona, 1997, pp. 40 y ss.; CAStiÑEIRA, cit. (n. 7), pp. 51 y ss; BAYlos, Antonio, "La prohibición de concurrencia desleal: Notas sobre la evolución legal y jurisprudencial", Temas Laborales, 1986, $\mathrm{N}^{\mathrm{o}} 8$, pp. 9-26.
}

${ }^{11}$ Nogueira, cit. (n. 10), p. 41. 
tratando de conciliar y garantizar el respeto a la libertad de trabajo y la iniciativa económica del individuo. ${ }^{12}$

\section{Fundamento jurídico y alcances conceptuales}

En general, la prohibición de concurrencia suele incluirse sistemáticamente dentro de los llamados deberes de conducta, en particular el deber de fidelidad, lealtad y buena $\mathrm{fe}^{13}$, los que genéricamente, impide abusar de la posición que ocupa el trabajador en la empresa perjudicando comercialmente al empleador. ${ }^{14}$

Esta afirmación no es ajena a nuestro ordenamiento. La doctrina mayoritaria y la jurisprudencia nacional han indicado que dicho supuesto causal se asocia a la noción de competencia desleal, derivando su fundamento del contenido ético jurídico del contrato de trabajo a partir de la obligación de lealtad, encontrando su origen en el deber de confianza y fidelidad. Estos deberes de conducta implícitos se desarrollan conjuntamente con la noción de buena fe, lo que conlleva la prohibición para el trabajador de competir deslealmente con su empleador..$^{15-16}$

Sin perjuicio de lo anterior, parte de la doctrina ha reconducido su fundamento únicamente a la buena fe, descartando ideas comunitaristas. ${ }^{17}$ Dicha posición observa al contrato de trabajo como un instrumento de intercambio de prestaciones y de satisfacción de intereses contrapuestos en el ámbito laboral, ${ }^{18}$ en el que por su naturaleza in non fancendo y marcado contenido patrimonial, la obligación de no concurrencia opera como forma

12 Rodríguez-PiÑEIro, Miguel, "Límites a la competencia y contrato de trabajo", Revista de Política Social, 1977, No 116, p. 9.

13 Rodríguez-Piñeiro, cit. (n. 12), p. 5; Ortega, Pompeyo, Poderes empresariales y resolución del contrato de trabajo por incumplimiento del trabajador, Comares, Granda, 2020, pp. 221 y ss.

${ }^{14}$ IrURetA, cit. (n. 9), p. 55.

${ }^{15}$ En esta línea, Thayer, William; NovoA, Patricio, Manual de Derecho del Trabajo, Editorial Jurídica de Chile, Santiago, 2019, T.4, p. 28; Etcheberry, Francoise, Derecho Individual del Trabajo, Legal Publishing, Santiago, 2011, p. 196; Lanata, Gabriela, Contrato Individual de Trabajo, Legal Publishing, Santiago, 2010, p. 276; Nadal, Daniel, El despido en el Código del Trabajo, Lexis Nexis, Santiago, 2003, p. 197; Gamonal, Sergio; Guid, Catherina, Manual del Contrato de Trabajo, Legal Publishing, Santiago, 2011, p. 282.

${ }^{16}$ Corte Suprema, 16 de noviembre de 2010, Rol No 5531-2010. En similar sentido, Corte de Apelaciones de Santiago, 31 de enero de 1995, Rol No 336-1994.

17 IrUReta, cit. (n. 9), p. 55; Pierry, Lucía, Derecho individual del trabajo, Ediciones Der, Santiago, 2018, p. 133.

${ }^{18}$ IRURETA, cit. (n. 9), pp. 57 y ss. 
de competencia desleal, que se enmarca en los deberes accesorios de la buena fe, dirigida a evitar causación de daños materiales en la empresa. ${ }^{19}$

Esta cuestión no es menor. Las posiciones que se asuman, por una parte, determinan la forma en que se proyectan las limitaciones a la libertad del trabajador durante la prestación laboral y, por otra parte, interceden en la definición de las restricciones o preferencias en el diseño de los mecanismos de protección de los intereses empresariales en el régimen sancionatorio laboral.

En efecto, la tesis que defiende una interpretación extensiva de la fidelidad $-\mathrm{y}$ hasta cierto punto que se proyecta a la buena fe desde su función integradora- propugna que las limitaciones de competencia, en su versión de competencia desleal, asciendan como un criterio de valoración jurídico y como fuente integrativa del contenido obligacional del contrato de trabajo, incorporando obligaciones implícitas que reducen los espacios de libertad de trabajo como contrapartida de la satisfacción de intereses empresariales.

\section{Algunas apreciaciones críticas}

Dicho lo anterior, no concordamos y refutamos la tesis que encuentra la justificación de esta causal en el contenido ético del contrato de trabajo y los deberes de fidelidad y lealtad. Lo mismo con respecto a las posiciones que fundamentan la obligación de no competencia en la buena fe. En mayor o menor medida, ambas tesis adoptan como eje una perspectiva comunitaria y armónica de intereses en la relación de trabajo, lo que constituye una limitante a la efectividad de los derechos fundamentales y a la configuración democrática del modelo de relaciones de trabajo. ${ }^{20}$

En efecto, la desigual distribución de poder entre el trabajador y el empresario, reflejado en la subordinación y dependencia como paradigma del poder privado, eleva el riesgo de eventuales menoscabos a los derechos fundamentales que, reforzada por la construcción de relaciones laborales comunitarias, genera un terreno fértil para el abuso del derecho.

Esto, por cuanto en el contrato de trabajo se producen inevitablemente conflictos de intereses más agudos que en otras formas contractuales, por lo que el ordenamiento jurídico debe velar por encontrar una regulación

\footnotetext{
${ }^{19}$ Nogueira, cit. (n. 10), pp. 142 y 143.

${ }^{20}$ Domínguez, Álvaro, “Análisis crítico al Derecho del Trabajo: entre el paternalismo y la emancipación”, Ius Novum, 2014, pp. 19-59.
} 
equilibrada de forma que, manteniéndose su naturaleza conflictual, se garantice la posibilidad de que cada contratante obtenga el objeto previsto en el contrato. En este caso, el cumplimiento correcto de las obligaciones contractuales requiere del reconocimiento específico de obligaciones instrumentales pero autónomas que no solo integren el contrato de trabajo, sino también que especifiquen y garanticen su contenido, lo que no es conciliable con la noción indeterminada y abierta de fidelidad. ${ }^{21}$

Lo anterior por cuanto mistifica la relación de trabajo al recurrir al interés objetivo empresarial de maximizar sus utilidades como cauce adecuado para definir los contornos de sus potestades con respecto a los trabajadores, en este caso, particularmente, su poder sancionatorio. ${ }^{22}$

En esta línea, tampoco creemos correcto reconducir el fundamento de la prohibición de competencia a la buena fe, ya que una de sus mayores proyecciones es en sede de ejecución contractual, lo que repercute en la determinación del contenido de la prestación de trabajo afectando su régimen disciplinario.

Esto es especialmente importante, ya que en materia laboral generalmente se habla de la función integradora de la buena fe como fuente de creación de obligaciones secundarias o implícitas en las que sus incumplimientos, dentro del marco sancionatorio, suponen el supuesto infraccional para aplicar una medida disciplinaria. En tal caso, al tenerse subentendidas o implícitas obligaciones de prestación genéricas, la conducta punible no será conocida previamente por el trabajador, sino hasta el momento de la determinación de su incumplimiento y comunicación de la imposición de una sanción laboral, lo que altera las reglas básicas de tipicidad en materia sancionatoria laboral.

El efecto criticado del contenido ético del contrato de trabajo es aquí extrapolable, ya que, en los hechos, la buena fe mantiene la idea de sumisión y subordinación indeterminada "aunque haya sido con la dulcificación" 23 que supone hablar de tal principio.

Por lo mismo, creemos en la necesidad de reformular el rol de la buena fe en la determinación del contenido obligacional del contrato de trabajo, en

\footnotetext{
${ }^{21}$ Rodríguez-PiÑEIro, cit. (n. 12) p. 7.

${ }^{22}$ Pedrajas, Abdón, "La prohibición de concurrencia postcontractual. Estudio crítico del artículo 74 de la ley de contrato de trabajo", Revista de Trabajo, 1976, № 56, p. 191.

${ }^{23}$ Nevado, María José, Las restricciones a la competencia en el contrato de trabajo, Editorial Tecnos, Madrid 1998, p. 67.
} 
el sentido de que más que ser fundamento de la obligación y tener una función integradora, representa la forma en la que esta debe cumplirse. Por esta razón, una vez determinados los alcances de la prohibición de competencia, la buena fe otorgará los parámetros según los cuales, razonablemente, el trabajador debe abstenerse de incurrir en la conducta prohibida, ${ }^{24}$ pero no imponer obligaciones no escrituradas o implícitas.

Por nuestra parte, estimamos que la causal en estudio debe ser entendida desde el conflicto de derechos fundamentales y la noción de competencia, estando determinada su funcionalidad desde una perspectiva constitucional que contraponga la libertad de empresa y la libertad de trabajo, siendo incompatible con conceptos jurídicos indeterminados — como la noción de fidelidad y buena fe- que no tienen relevancia en nuestro orden social a nivel constitucional.

De esta forma, el correcto planteamiento del fundamento de la obligación de no concurrencia, prohibición de competencia o competencia desleal, se debe realizar desde la libertad de empresa en el marco de una economía de mercado. ${ }^{25}$ Solo así pueden valorarse las particularidades que se producen en la extinción del contrato de trabajo, con el fin de permitir calibrar adecuadamente la calificación de ilegalidad de conductas ejercidas por el trabajador al amparo de la libertad de trabajo, cuando ponderativa no tiene la aptitud para afectar objetivamente la actividad empresarial.

En dicho escenario, en el sentido y función de las normas limitativas de la concurrencia en materia laboral, confluye la idea del pluriempleo como respuesta a la insuficiencia de los salarios y las formas precarias de trabajo, que fuerza al trabajador a la búsqueda de otra ocupación lucrativa que le permita cubrir sus necesidades, debiendo ser conciliadas las restricciones de comportamiento con la eficacia de la garantía constitucional de la libertad de trabajo. ${ }^{26}$

Creemos en descartar aquella concepción comunitarista asumida por la doctrina, que otorga un valor excepcional a la obligación de lealtad y fidelidad como rasgo definitorio típico de la relación de trabajo. Nos parece una pretensión oportuna la adecuación de los estándares doctrinarios de las vicisitudes en el régimen del despido disciplinario a los esquemas

\footnotetext{
${ }^{24}$ CAJAS, Alejandra, "La prohibición de competencia desleal en el contrato de trabajo", Actas II Congreso Nacional Estudiantil de Derecho del Trabajo, 2012.

${ }^{25}$ Baylos, cit. (n. 10), p. 9.

${ }^{26}$ RodríGUEZ-PIÑEIRo, cit. (n. 12), p. 13.
} 
cambiarios del contrato de trabajo, sin adherencia personalista, sino más bien sometida a los elementos objetivos y garantistas que contextualicen la relación de trabajo desde la desigualdad de poder desde la eficacia de los derechos fundamentales. ${ }^{27}$

4. ¿Competencia desleal u obligación de no concurrencia? Entre la objetividad y subjetividad de los ilícitos de no competencia laboral

La noción de competencia supone una situación de oposición o contienda entre determinados sujetos para el logro de sus fines económicos en la medida que aparezcan como coincidentes en su ámbito de actuación, siendo mutuamente excluyentes, ascendiendo su regulación como necesaria para el desarrollo correcto del modelo social organizativo dictado por el capitalismo. Los ordenamientos jurídicos pretenden la delimitación de formas lícitas e ilícitas de competencia a fin de evitar la concentración y centralización del capital, como también encauzar las nuevas formas de consumo de masas y publicidad. ${ }^{28}$

En este caso, la concurrencia mercantil es relevante para el derecho cuando se conecta con las normas necesarias para su protección, las que generalmente se orientan en dos grupos: las disposiciones que integran la normativa sobre las prácticas restrictivas de la competencia y las disposiciones que tipifican y sancionan formas de comportamiento ilícitos. Es la última vertiente la que asume centralidad en materia laboral. ${ }^{29}$

Esta perspectiva proyecta, tanto en las relaciones basadas en la cooperación (asociativas) como en la subordinación (prestación de servicios por cuenta ajena), una doble caracterización y modalidad: las normas reguladoras que se enfocan en las prohibiciones de competencia absoluta en sentido subjetivo o las disposiciones normativas que preconfiguran prácticas objetivamente desleales vinculadas al medio utilizado para concurrir.

En las prohibiciones subjetivas de concurrencia se tiende a prescindir del elemento objetivo para configurar un mandato de abstención puro, constituyendo las limitaciones de concurrencia cláusulas de interdicción

\footnotetext{
${ }^{27}$ BAYLos, cit. (n. 10), p. 23.

${ }^{28}$ BAYlos, cit. (n.10), pp. 9-10. Se hace la observación que en los siguientes apartados seguiremos el razonamiento tipológico del autor con el fin de situar la perspectiva de debate en el ordenamiento jurídico chileno.
}

${ }^{29}$ BAYLOS, cit. (n. 10), pp. 9-10. 
similares a las de plena dedicación. En cambio, en las prácticas desleales, su desarrollo viene dado por comportamientos contrarios a los usos honestos en materia industrial y comercial en las que, debido a la vinculación asociativa o de subordinación, su conocimiento en la organización y esfera de actuación en ella sitúan al trabajador en una posición de competencia en la que el desarrollo de acciones concurrentes, en tales circunstancias, serían contrarias a la buena fe. ${ }^{30}$

Frente a este predicamento, es inevitable preguntarnos cuál es el modelo de prohibición de competencia asumido por el legislador laboral chileno en materia de despido disciplinario.

La doctrina laboral en Chile ha asumido que la causal contenida en el 160 número 2 del Código del Trabajo es una hipótesis de competencia desleal, sin diferenciar la incidencia de la noción de competencia ilegal y sus fórmulas de regulación. En este contexto, se indica que el fundamento de este motivo disciplinario se encuentra en el contenido ético del contrato, en particular en que "el deber de confianza conlleva la prohibición para el trabajador de competir deslealmente con su empleador". ${ }^{11}$

Como observaremos, esta perspectiva extiende desmesuradamente el alcance de este supuesto habilitante extintivo en la medida que justifica el término del contrato de trabajo, incluso en los casos en que no existe prohibición expresa del ejercicio de una actividad, como también al prescindir del perjuicio por su irrelevancia para ponderar la desvinculación. Lo que se sanciona es un comportamiento contrario a la buena fe y los deberes de fidelidad y lealtad.

Esta tesis vincula la causal al medio utilizado para concurrir, reprochando el comportamiento en abstracto con independencia del resultado: el desarrollo de otros trabajos cuyos resultados vayan dirigidos a la misma clientela del empleador, el aprovechamiento de conocimientos adquiridos en la empresa a que se hace competencia, o bien, el prevalerse de la información que ha podido proporcionar o proporciona la presencia en el interior de la organización productiva, entre otros. ${ }^{32}$

\footnotetext{
${ }^{30}$ Baylos, cit. (n. 10), pp. 10-11.

31 Gamonal y Guidi, cit. (n. 15), p. 282. En similar sentido aludiendo a expresiones vinculadas a deberes de conductas de idelidad y lealtad, THAYER y NovOA, cit. (n. 15), p. 28; EtcheBerRy, cit. (n. 15), p. 196; Nadal, cit. (n. 15), p. 197; Irureta, cit. (n. 9), pp. 63 y ss; Vivanco, Manuel, El Despido Laboral, Editorial Jurídica de Chile, Santiago, 1994, p. 67; Lizama Portal, Luis; Lizama Castro, Diego, Manual de Derecho Individual del Trabajo, DER, Santiago, 2019, p. 246.
}

${ }^{32}$ Irureta, cit. (n. 9), p. 63; Lizama y Lizama, cit. (n. 31), p. 246. En similar sentido, en el derecho 
Así, a modo de síntesis, la tesis de la competencia desleal no solo configura el comportamiento reprochable cuando se vulneran obligaciones convencionales expresas o específicas, sino también por comportamiento o actos que vulneren la obligación genérica de buena fe, o deberes como lealtad o fidelidad, sean expresos o implícitos, ampliando la extensión causal del ilícito.

En función de lo anterior, creemos que la opción correcta es entender la causa del artículo 160 número 2 del Código del Trabajo desde el foco de la prohibición de negociaciones, es decir, como una obligación de no concurrencia de carácter relativo.

En primer orden, desde un estricto punto positivista, la estructura del tipo laboral no describe la conducta prohibida como una hipótesis de competencia desleal, sino que expresamente se delimita al incumplimiento de una obligación de no hacer, configurada por la prohibición de ejecutar negociaciones dentro del giro del negocio que expresamente se consigne en el contrato de trabajo. ${ }^{33}$

En tal supuesto, la configuración del ilícito viene dada por la infracción de una obligación de abstención en la que el trabajador, como deudor de la prestación de trabajo, debe observar la ejecución de un comportamiento negativo, delimitado subjetiva, pero relativamente, a no realizar determinadas actividades comerciales o laborales que estén dentro del giro del negocio. De esta forma, desde un punto de vista normativo, lo sancionado no es un comportamiento desleal, sino el incumplimiento de una obligación de no hacer.

Por otra parte, en un segundo nivel, la noción de competencia desleal se contradice con las funciones de la tipicidad como límite al ejercicio del poder disciplinario. La tipicidad busca determinar claramente la selección de comportamientos relevantes para el régimen disciplinario y la descripción de los hechos sancionables, buscando garantizar que solo podrán castigarse las conductas que se hallen descritas previamente en algún cuerpo normativo, ${ }^{34}$ el cual, según sus estándares de configuración normativa, no puede ser tan vago y difuso que atribuya al empresario una facultad incondicional para

comparado, Aguilera, Raquel, Las causas de Despido Disciplinario y su valoración por la jurisprudencial, Thomson Reuters Aranzadi, Madrid, 1997, pp. 82 y ss.

${ }^{33}$ En otros casos, la legislación chilena expresamente ha calificado los ilícitos que atentan contra la competencia como de "competencia desleal", como ocurre con la Ley 20.169.

${ }^{34}$ GIL y Gil, José Luis, Autotutela privada y poder disciplinario en la empresa, Centro de Publicaciones del Ministerio de Justicia, Madrid, 1993, p. 37 y ss. 
ejercer el poder disciplinario. ${ }^{35}$

Pues bien, a partir de la idea de buena fe y el contenido ético que dan sustento a la noción de competencia desleal, la función garantista de la tipicidad se ve afectada por cuanto la lealtad y la fidelidad como estándares de conducta no solo ascienden como un criterio de valoración jurídico, sino también como una fuente integrativa del contenido obligacional del contrato de trabajo, extendiendo su alcance al incorporar obligaciones implícitas que justificarían un poder disciplinario de contornos ambiguos e imprecisos.

Finalmente, y ya en un tercer orden, la proyección de los derechos fundamentales despliega su eficacia al momento de comprender el diseño legal de la justa causa extintiva, por cuanto este no puede significar la reducción de los espacios de libertad de trabajo como contrapartida de la satisfacción de intereses empresariales de manera desproporcionada, premisa que obliga a reconfigurar la identidad de esta causal bajo valores normativos constitucionales y no simplemente contractuales.

En esta perspectiva debemos partir de un supuesto básico, que es asumir la licitud del pluriempleo en nuestro ordenamiento jurídico como expresión de la garantía constitucional de la libertad de trabajo y su protección. ${ }^{36}$ En esta línea, el artículo 160 número 2 del Código del Trabajo mediatiza y restringe tal garantía constitucional a favor de la libertad de empresa y propiedad, pero no de toda actividad o cualquiera, sino de aquella que se dé dentro de los términos estrictamente legales que permiten su restricción y que, además, razonable y objetivamente, sitúen al trabajador en un punto de conflicto en relación con los intereses competitivos del empleador. ${ }^{37}$ De esta forma, la interpretación de dicha norma, por constituir una restricción de orden legal de la garantía constitucional de la libertad de trabajo y su protección, debe realizarse de manera restrictiva, siendo limitado y excepcional el alcance que debe darse a la misma.

Consideramos que esta tesis es adecuada, por cuanto su estructura se desarrolla dentro de las coordenadas propias del ámbito contractual. Si bien reconoce que el modelo causal que mediatiza el derecho de la libertad de trabajo a favor de los intereses empresariales acota su campo de protección

\footnotetext{
${ }^{35}$ Fernández, María, El poder disciplinario en la empresa, Civitas, Madrid, 1991, pp. 40 y ss.

${ }^{36} \mathrm{Al}$ respecto, ver CAJAS, cit. (n. 24). En la jurisprudencia reconociendo el pluriempleo como elemento interpretativo de esta causal, Corte de Apelaciones de San Miguel, 9 de noviembre de 2015, Rol N ${ }^{\circ}$ 308-2015.

${ }^{37}$ Esta reflexión no es propia de nuestro ordenamiento jurídico. Se observa en figuras similares de otros ordenamientos, como es el caso del español. Sobre el punto NogueIRA, cit. (n. 10), pp. 200 y ss.
} 
a fin de impedir una pretensión expansiva de una obligación de abstención desproporcionada, mediante parámetros ambiguos y genéricos, como los que permite desarrollar la tesis de la competencia desleal.

De esta forma, creemos en la necesidad de asumir una visión finalista, en la que los criterios ponderativos sean establecidos expresamente por el ordenamiento jurídico mediante la ley y no subentendidos ni preconfigurados arbitrariamente por la autonomía de la voluntad.

\section{LA CONDUCTA PROHIBIDA: LAS NEGOCIACIONES INCOMPATI- BLES DENTRO DEL GIRO DE LA EMPRESA}

\section{Negociación incompatible: límites y alcances de la conducta prohibida}

a) ¿Obligación de no concurrencia o prohibición de competencia desleal? Como en el resto de las causales disciplinarias, nuestra legislación ha delimitado la conducta prohibida mediante conceptos abiertos e indeterminados. En el caso de la causal contenida en el artículo 160 número 2 del Código del Trabajo, la expresión utilizada para definir la conducta punible es la de "negociaciones que ejecute el trabajador dentro del giro del negocio".

Esto reconduce a dos problemas interpretativos en relación con la extensión de núcleo prohibido: cuál es la conducta ilícita y cuál es el objeto de protección, en el sentido de si lo sancionado es el incumplimiento de una obligación de no concurrencia o bien una hipótesis de prohibición de competencia desleal. ${ }^{38}$

Normativamente, lo sancionado es el incumplimiento de una obligación de no hacer, configurada por la prohibición de ejecutar negociaciones dentro del giro del negocio.

En este supuesto, la configuración del ilícito viene dada por la infracción de una obligación de abstención en la que el trabajador, como deudor de la prestación de trabajo, debe observar la ejecución de un comportamiento negativo. Por lo mismo, para que opere esta causa, es necesario que la actividad prohibida "se ejecute de manera efectiva, no bastando las meras insinuaciones u ofrecimientos". 39

\footnotetext{
${ }^{38}$ Sobre esta discusión y la tesis asumida, Supra II.3.

39 Etcheberry, cit. (n. 15), pp. 196 y ss. En similar sentido, Corte de Apelaciones de Puerto Montt, 13
} 
Con respecto al contenido de la actividad concurrente, la doctrina mayoritaria entiende la expresión "negociaciones" como toda operación o actividad derivada de una ocupación o labor lícita, ${ }^{40}$ alcanzando tanto actividades laborales como comerciales.

Por tanto, "los actos prohibidos al trabajador deben estar configurados por la sucesiva colocación sobre el mercado del bien o el producto, que suponga la oferta de bienes y servicios iguales o de similar naturaleza a los del empleador", más allá de la condición contractual que tenga, ${ }^{41}$ alcanzando actividades laborales realizadas fuera del horario por el trabajador que se emplea para la empresa de la competencia a partir de la buena fe. ${ }^{42}$

De esta forma, la prohibición alcanza tanto la actividad realizada por cuenta de otros empleadores como la ejecutada por cuenta propia, ${ }^{43}$ fundada en que la empresa principal, no solo remunera su trabajo, sino que le facilita medios para adquirir perfeccionamiento y experiencia profesional que luego el empleado pretende utilizar en propio provecho o de otros con notorio y evidente perjuicio para los intereses de quien depositó en él su confianza. ${ }^{44}$

Por lo mismo, para esta tendencia interpretativa, es sancionable tanto la concurrencia ejecutada en términos de subordinación y dependencia, como la realizada asociativamente, siendo una hipótesis de competencia desleal "si el trabajador lleva a cabo actividades productivas por cuenta propia, sea como autónomo en sentido estricto o como miembro actividad

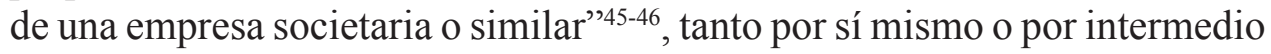

de noviembre de 2006, Rol No 156-2006.

${ }^{40}$ Gamonal y Guidi, cit. (n. 15), p. 283; Irureta, cit. (n. 9), p. 59; Vivanco, cit. (n. 31), p. 67. En la jurisprudencia, Juzgado de Letras del Trabajo de Iquique, 29 de agosto de 2012, Rol No O-49-2012; $1^{\circ}$ Juzgado de Letras del Trabajo de Santiago, 6 de noviembre de 2013, Rol No O-3016-2013.

${ }^{41}$ IruRETA, cit. (n. 9), p. 59.

42 Vergara, Rafael, Terminación del Contrato de Trabajo, Editorial Metropolitana, Santiago, 2014, T.II, p. 247. En un sentido contrario en la jurisprudencia, $1^{\circ}$ Juzgado de Letras del Trabajo de Santiago, 23 de diciembre de 2011, Rol No O-3002-2011.

${ }^{43}$ Similar circunstancia se observa en el derecho español. Sobre el punto, ver AguilerA, cit. (n. 32), p. 83.

${ }^{44}$ Aguilera, cit. (n. 32), p. 82.

${ }^{45}$ SEMPERE, Antonio, "Despido disciplinario y preparación de la competencia desleal", Aranzadi Social, $1991, \mathrm{~N}^{\circ} 5$, p. 27 y ss.

${ }^{46}$ No obstante, nuestra jurisprudencia ha sido vacilante. Así, se ha resuelto que "lo que prohíbe el artículo 160 número 2 del Código del Trabajo es efectuar negociaciones que caigan dentro del giro del negocio, en tanto forma parte de una sociedad no es lo mismo que efectuar o ejecutar negociaciones, por ser la calidad asociativa distinta de la operativa o negociadora". Véase Corte de Apelaciones de Santiago, 21 de octubre de 2004, Gaceta Jurídica, № 292, octubre de 2014, p. 263. En sentido contrario, 
de terceros. ${ }^{47}$

Por nuestra parte, en cuanto a qué entender por negociaciones y a propósito del núcleo prohibido de la concurrencia, creemos que esta supone, según el uso natural y obvio de las palabras, la acción o efecto de tratar, es decir, comerciar, comprando, vendiendo o cambiando géneros, mercaderías o valores para aumentar el caudal, ${ }^{48}$ por lo que, en una primera lectura, lo que configuraría lo prohibido sería la ejecución por parte del trabajador de actividades mercantiles que compitan con las que son propias del giro del empleador, que excluyen relaciones sociales en las que participa bajo subordinación, dependencia y ajenidad laboral para otros empleadores.

De esta forma, el non facere vendría dado por la abstención de ejecución de actividades mercantiles o civiles por cuenta propia, autónomas o de carácter asociativo, que se encuentren dentro del giro del empleador y no así actividades laborales. ${ }^{49}$

Por lo mismo, lo sancionado es la organización civil o comercial de empresas o la realización de actividades mercantiles que pretendan la colocación de bienes y servicios similares a los ejecutados por la organización empresarial en que presta servicios subordinadamente, en la que debido a los conocimientos técnicos laborales y las funciones desempeñadas para su empleador, entra a competir fuera de los márgenes aceptados en el tráfico mercantil en el esquema de la libre competencia, excluyendo actividades bajo términos de subordinación y dependencia, siendo solamente sancionables en la medida que impidan el cumplimiento de la prestación laboral a la que se encuentra obligado, lo que excede el contenido de esta causal.

Esta interpretación nos parece armónica con el ejercicio y la eficacia de la libertad de trabajo y el pluriempleo, como también con el fundamento de esta causal enfocada en la defensa de la libre competencia.

Corte Suprema, 28 de mayo de 2002, Rol No 747-2002.

${ }^{47}$ Sempere, cit. (n. 45), p. 30. Asumiendo en Chile esta postura Irureta, cit. (n. 9), pp. 59-60; GAmOnAL y Guidi, cit. (n. 15), p. 283; NADAL, cit. (n. 15), p. 197.

${ }^{48}$ En la jurisprudencia, véase Juzgado de Letras del Trabajo de Chillán, 15 de enero de 2016, Rol No O-272-2015; $2^{\circ}$ Juzgado de Letras del Trabajo de Santiago, 3 de julio de 2012, Rol No O-1073-2012; $2^{\circ}$ Juzgado de Letras del Trabajo de Santiago, 30 de julio de 2011, Rol N ${ }^{\circ}$ O-602-2011; $2^{\circ}$ Juzgado de Letras del Trabajo de Santiago, 8 de enero de 2015, Rol No T-303-2014; Juzgado de Letras del Trabajo de Iquique, 25 de junio de 2012, Rol N O-63-2012; Juzgado de Letras del Trabajo de Santiago, 6 de abril de 2015, Rol No O-4581-2014.

${ }^{49}$ En un sentido similar, pero no de manera expresa, Macchiavelo, Guido, Derecho del Trabajo, Fondo de Cultura Económica, México, 1986, T. I, p. 520. 


\section{b) La actividad concurrente.}

Ahora, más allá del debate anterior, cabe preguntarse qué tan amplio es el contenido de la actividad concurrente. ¿La concurrencia prohibida exige que el trabajador desarrolle una segunda actividad productiva en sentido estricto o, por el contrario, también tiene lugar solo cuando esta implicado de una forma indirecta $?^{50}$ Nuevamente, el Código del Trabajo nada indica.

Para un sector doctrinario, el simple hecho de participar indirectamente en una empresa, por ejemplo, mediante la aportación de capital, supone concurrencia desleal. De esta forma, se sanciona tanto al verificar personalmente la actividad laboral o comercial competitiva, sea por su similitud y finalidad, como también al facilitar los medios económicos con fines lucrativos para la elaboración y lanzamiento ulterior al mercado de estos mediante formas de organización empresarial, ya sean societarias, civiles o comerciales. ${ }^{51}$

Desde nuestra perspectiva, no parece correcto extender la obligación de abstinencia a todos los supuestos en que el trabajador se relacione con otra empresa competidora. En principio - y dentro de los márgenes de la tesis mayoritaria-, solo sería coherente sancionar una actividad que conlleve competencia a partir de la ejecución de una prestación, de un hacer técnico en el que el trabajador despliegue tanto los conocimientos como las técnicas obtenidas de su empleador para realizar la actividad propia de su giro para con terceros.

Por lo mismo, ponderativamente, no vemos cómo podría verse afectado el fundamento de esta causal por el solo hecho de participar indirectamente en otra sociedad, sea como accionista o socio, en el que su actividad solamente se limita al aporte o participación patrimonial. Por lo mismo, creemos que la concurrencia prohibida solo alcanza a la segunda actividad desarrollada en un sentido estricto y no cuando se trata de una forma indirecta.

En cuanto a la habitualidad, para la doctrina bastaría una sola

\footnotetext{
${ }^{50}$ Esta misma interrogante es planteada con respecto al modelo disciplinario laboral español por Aguilera, cit. (n. 32), pp. 90 y ss.

${ }^{51}$ Sobre el punto, véase Agullera, cit. (n. 32), p. 91. Sosteniendo esta tesis amplia en Chile IrURETA, cit. (n. 9), pp. 58 y ss. En la jurisprudencia, sosteniendo la tesis restrictiva, Juzgado de Letras del Trabajo de Puente Alto, 31 de agosto de 2015, Rol No O-86-2015; Juzgado de Letras del Trabajo de Valparaíso, 6 de mayo de 2010, Rol No O-731-2009; $2^{\circ}$ Juzgado de Letras del Trabajo de Santiago, 30 de julio de 2011, Rol No O-602-2011; Corte de Apelaciones de Valparaíso, 10 de marzo de 2016, Rol $\mathrm{N}^{\mathrm{o}} 16-2016$.
} 
negociación que perjudique los intereses del empleador para concluir que se ha configurado la causal, por cuanto la gravedad no viene dada por la repetición de los hechos en el tiempo, sino más bien por el quiebre de la perdida de confianza, fundado en que la no concurrencia es una hipótesis de competencia desleal vinculada a la buena fe y a los deberes de fidelidad y lealtad. ${ }^{52}$

No obstante, una lectura literal del texto normativo nos llevaría a la conclusión de que lo exigido por el legislador es una cierta habitualidad, ya que la conducta prohibida es definida en plural, por lo que, en estricto rigor, un acto esporádico no constituirá una falta grave punible con la extinción del contrato.

A nuestro entender, el legislador no sanciona aquellas conductas consistentes en simples actos aislados, extraordinarios o especiales, por estimarlos incapaces de afectar los intereses empresariales. El objeto y fundamento de lo protegido no es la pérdida de confianza o atentados a lealtad, sino más bien la violación de una obligación de non facere que viene configurada por expreso mandato legislativo desde la pluralidad de actuaciones, es decir, por la sucesiva colocación sobre el mercado del bien o el producto que suponga la oferta de bienes y servicios iguales o de similar naturaleza a los del empleador y que, como tales, tengan la aptitud ponderativa, en términos de relevancia, de constituir una forma de competencia fuera los márgenes permitidos en un esquema de libre mercado.

No obstante, lo anterior no es excluyente de que la gravedad de la conducta sea reprochable por un solo acto. En este contexto, lo reprochado, a nuestro entender, es tanto lo cuantitativo como cualitativo, lo que deberá ponderarse según la gradualidad sancionatoria que impone la aplicación del principio de proporcionalidad en materia punitiva laboral.

\section{Dentro del giro del negocio}

Un segundo elemento normativo viene dado por la exigencia de que las negociaciones ejecutadas por el trabajador estén dentro del giro del negocio, delimitando el ámbito de la actividad prohibida.

En cuanto a la definición de esta noción, la doctrina ha dicho que son "aquellas a que se dedica la empresa donde [el trabajador] presta sus

${ }^{52}$ IrUReta, cit. (n. 9), p. 61; Gamonal y Guidi, cit. (n. 15), p. 283. 
servicios". ${ }^{53}$ En otros términos, el giro del negocio lo constituye el objeto propio de la actividad que realiza la empresa, el quehacer de su especificidad como tal ${ }^{54} \mathrm{o}$, en otros términos, "las operaciones ordinarias que efectúa la empresa cuya titularidad pertenece al empleador". ${ }^{55}$

Para este efecto, su determinación no solo será dada por el sustrato fáctico de la actividad, sino también por las normas comerciales que regulan la misma, ${ }^{56}$ lo que desde un punto de vista práctico se identifica con "el giro que se declara para efectos tributarios". ${ }^{57}$

Esto es de suma importancia, por cuanto no podrían prohibirse actividades que se encuentren fuera del giro de la empresa, ${ }^{58}$ ya que se estaría vulnerando la garantía constitucional de libertad de trabajo, ${ }^{59}$ siendo contrarias al orden público aquellas cláusulas contractuales que excedan su ratio prohibitiva.

En este esquema, como señala la tesis de la competencia desleal, el cumplimiento de este requisito debe matizarse, ya que no "cualquier concurrencia sirve de fundamento para explicar la extinción del contrato". En efecto, "no es posible identificar prohibición de competencia con el simple ejercicio de una segunda actividad por cuenta propia o ajena", ${ }^{60}$ sino solamente cuando esta tiene los rasgos de desleal, es decir, cuando concurre en el mismo plano que la empresa principal, sobre un mismo mercado y sobre idéntico círculo potencial de clientes. ${ }^{61}$

Aparentemente, dicha tesis sería limitativa del ilícito por cuanto la reprochabilidad de la conducta vendría dada por la idea de la buena fe. No obstante, como contrapartida, permite o justifica la sanción disciplinaria incluso en aquellos casos en que no se haya prohibido el ejercicio de la

${ }^{53}$ WALKer, Francisco, Derecho de las Relaciones Laborales, Editorial Universitaria, Santiago, 2003, p. 56. En la jurisprudencia, Corte de Apelaciones de Concepción, 2 de julio de 2015, Rol No 100-2015.

${ }^{54}$ Gamonal y Guidi, cit (n. 15), p. 283; Irureta, cit. (n. 9), p. 62.

${ }^{55}$ IRURETA, cit. (n. 9), p. 62.

${ }^{56}$ IRURETA, cit. (n. 9), p. 62.

${ }^{57}$ LanATA, cit. (n. 15), p. 276; NADAL, cit. (n. 15), p. 198. En la jurisprudencia, Corte de Apelaciones de Concepción, 2 de julio de 2015, Rol No 100-2015.

${ }^{58}$ LANATA, cit. (n. 15), p. 276.

${ }^{59}$ NADAL, cit. (n. 15), p. 198.

${ }^{60}$ IRURETA, cit. (n. 9), pp. 63-64.

${ }^{61}$ IrURETA, cit. (n. 9), p. 65. En la jurisprudencia, $2^{\circ}$ Juzgado de Letras de San Fernando, 16 de agosto de 2012, Rol No O-18-2012 
actividad, ${ }^{62}$ ya que su configuración $\mathrm{v}$ iene $\mathrm{d}$ ada $\mathrm{d}$ esde 1 os d eberes de conducta morales dictados por el contenido ético del contrato de trabajo.

Por nuestra parte, si bien concordamos con la matización anterior, creemos que su justificación no deriva de la naturaleza de la negociación incompatible con el giro de la actividad ni de su tipicidad. La ley laboral no identifica en ningún lugar el ilícito del artículo 160 número 2 del Código del Trabajo con la noción de competencia desleal, sino que establece una prohibición de actuación, una obligación de no hacer, la cual, en cuanto regla, no contempla como elemento del tipo la deslealtad.

No obstante, y de manera distinta, es que consideremos la identificación de la concurrencia en los niveles objetivos y subjetivos de competencia como parte de la condición de punibilidad del ilícito, a propósito de la proporcionalidad o ponderación como elemento de gravedad y la correspondencia con la sanción disciplinaria. En este caso, la buena fe otorgará los parámetros según los cuales el trabajador, razonablemente, debe abstenerse de incurrir en la conducta prohibida, pero no como un elemento estructural del ilícito, sino más bien como estándar de comportamiento y no en su función integradora.

\section{Que conste la prohibición por escrito}

Como se desprende del texto, y como reconoce parte de la doctrina y de la jurisprudencia, esta causa además exigiría que las negociaciones incompatibles hubieran sido prohibidas en el respectivo contrato de trabajo, ${ }^{63}$ pudiendo incluso estar en reglamento interno ${ }^{64}$ de manera que, si faltase esta estipulación, no se configuraría la causal. ${ }^{65}$

No obstante la claridad de la norma, para un importante sector doctrinario $^{66}$ la redacción utilizada por el legislador es equivocada, ya que

\footnotetext{
${ }^{62}$ IruReta, cit. (n. 9), p. 63.

${ }^{63}$ Rojas, Irene, Derecho Individual del Trabajo, Editorial Thomson Reuters, Santiago, 2015, pp. 418 y ss.; PIERry, cit. (n. 17), pp. 133 y ss; ThaYer y Novoa, cit. (n. 15), p. 54.

${ }^{64}$ Gamonal y Guidi, cit. (n. 15), p. 284; Etcheberry, cit. (n. 15), p. 196; Walker, Francisco, Nuevas Normas. Terminación del contrato de trabajo, 1990, p. 56.

${ }^{65}$ GaEte, Alfredo, Tratado de Derecho del Trabajo y Seguridad Social, Editorial Jurídica, Santiago, 1967, T.I, p. 243, LANATA, cit. (n. 15), p. 277.

${ }^{66}$ En esta línea, Irureta, cit. (n. 9), pp. 58 y ss.; Lanata, cit. (n. 15), p. 277. Thayer y Novoa, cit. (n. 15), p. 53; NADAL, cit. (n. 15), p. 199. Reseñando jurisprudencialmente tal posibilidad, véase Lizama, Luis, Derecho del Trabajo, Editorial Lexis Nexis, Santiago, 2003, pp. 176 y ss.
} 
la obligación de lealtad y de prohibición de competencia desleal fluyen del contenido ético jurídico del contrato de trabajo y, como tal, obligan al deudor de trabajo con independencia de la escrituración de prohibición, por lo que "este requisito pareciera estar de más". ${ }^{67}$

Esto se fundamenta en que la honradez no podría, como principio de conducta y norma ética, quedar sujeta a la existencia de una disposición que así lo diga expresamente, pudiendo extinguirse el contrato de trabajo por comprometer seriamente los intereses del empleador. ${ }^{68}$

Por este motivo, "la prohibición debe presumirse" y lo que corresponde, a la inversa, es que el empleador autorice expresamente que el trabajador pueda realizar negociaciones incompatibles con el giro del negocio. Así, con la finalidad de superar el "error en la redacción" de la causal del artículo 160 número 2 del Código del Trabajo, se propone que, en el caso de que en el contrato no aparezca estampada la prohibición, podría aplicarse la causal de falta de probidad o incumplimiento grave de las obligaciones como causal justificada, alterando las reglas de tipicidad. ${ }^{69}$

Es más, se indica — sin fuente normativa - que "la regla general es la prohibición de concurrencia desleal, la que solo se puede alterar en caso de autorización del empleador", agregándose que la prohibición debe entenderse "subsistente salvo que el empleador otorgue su consentimiento en orden a considerar que la actividad paralela del dependiente es compatible con el interés general de la empresa". ${ }^{70}$

Es importante precisar que no concordamos con lo anterior. Del tenor de la norma, se desprende como requisito copulativo que la prohibición debe constar por escrito y expresamente, no bastando que hubiese sido prohibida verbalmente.

No nos parece prudente entender que las prohibiciones deban ser entendidas como implícitas, subentendidas o presuntas, ya que como indicamos, en el régimen sancionatorio laboral debe existir una tipificación expresa y estricta de las conductas sancionables, por lo que las cláusulas

\footnotetext{
${ }^{67}$ Gamonal y Guidi, cit. (n. 15), p. 284.

${ }^{68}$ NADAL, cit. (n. 15), p. 199.

${ }^{69}$ Thayer y Novoa, cit. (n. 15), p. 408; NADAL, cit. (n. 15), p. 199. No obstante, Melis y Sáez entiende que no es posible extender de esta forma la causalidad de la falta de probidad, por cuanto no parece razonable la configuración de un llamado contenido ético jurídico en el contrato de trabajo. Véase Melis, Cristián; SÁez, Felipe, El Contrato Individual de Trabajo en los Dictámenes de la Dirección del Trabajo, Legal Publishing, Santiago, 2009, p. 284.
}

${ }^{70}$ IrURETA, cit. (n. 9), p. 69. 
genéricas y normas en blanco que fundan la aplicación de una causal de despido serían contrarias a nuestro modelo causal disciplinario en la medida que la tipicidad, en cuanto garantía, se satisface con disposiciones reguladoras de comportamientos específicos y claros.

Esto se debe a que la noción de tipicidad pretende fundar la responsabilidad del trabajador sobre la previsibilidad de la sanción y excluir el margen de discrecionalidad en su aplicación, por lo que la no satisfacción de este estándar no permite el nacimiento y justificación lícita del poder disciplinario. ${ }^{71}$

Es más, desde la perspectiva de la buena fe que justificaría esta posición de obligaciones implícitas, presuntas o subentendidas, el ejercicio del poder disciplinario debe ser delimitado, siendo contrario a esta su utilización "por sorpresa", ya que, niega el núcleo básico de confianza mutua en que descansa el contrato, y al mismo tiempo implica una desviación en la operatividad del poder disciplinario, que se utilizaría desconociendo la finalidad de prevención especial y general que es su signo de reconocimiento. ${ }^{72}$

Precisamente, es aquí donde se produce el punto de contacto entre la buena fe y la interdicción de la arbitrariedad que está en la base del principio de tipicidad, siendo su función imponer claridad en la descripción e indicación de las prohibiciones en el seno de la empresa, marcándose con precisión el ámbito de lo ilícito, de manera que los trabajadores puedan ordenar su conducta a una norma de comportamiento, lo cual no se cumple con un contenido indeterminado de obligaciones imprecisas, de las que su infracción puede derivar en la extinción del contrato. ${ }^{73}$

Desde otra perspectiva, como señala Cajas, el legislador interviene normativamente y regula de modo expreso la obligación de no competencia con el fin de evitar la sobreprotección empresarial y no solo el abuso en el que podría desembocar la total ausencia de regulación, sino también la correlativa negociación individual de su contenido. Así, si se permite que la buena fe derogue la exigencia expresa de escrituración, existirá "siempre incertidumbre para el trabajador, por cuanto este no sabrá” si la prohibición le resulta aplicable o no sino hasta el momento en que esto se decida en un eventual juicio, de acuerdo con el criterio del juez que conozca del asunto. ${ }^{74}$

\footnotetext{
${ }^{71}$ SuppIEJ, Giuseppe, Il rapporto di lavoro. Costituzione e svolgimento, CEDAM, 1982, pp. 147 y ss.

${ }^{72}$ GIL y GIL, cit. (n. 34), p. 85.

${ }^{73}$ GIL y GIL, cit. (n. 34), p. 85.

${ }^{74}$ CAJAs, cit. (n. 24).
} 
Finalmente, y desde un enfoque constitucional, ${ }^{75}$ las obligaciones que pudieran entenderse implícitas en el contrato de trabajo tienen el límite de lo que es permitido por la ley, especialmente cuando se confrontan con una garantía individual como es la libertad de trabajo y su protección, contenida en el número 16 del artículo 19 de la Constitución Política, según el que ninguna clase de trabajo puede ser prohibida, salvo que se oponga a la moral, a la seguridad o a la salubridad pública, que lo exija el interés nacional y que una ley lo declare así. La excepción es la prohibición permitida en el número 2 del artículo 160 del Código del Trabajo, que como tal no puede aplicarse por similitud ni interpretarse ampliamente al grado de elevar obligaciones subentendidas o implícitas como limitantes de la eficacia de un derecho fundamental, cuando expresamente el texto legal no lo permite.

En este contexto, creemos que la sanción contenida en el artículo 160 número 2 del Código del Trabajo únicamente se aplicará a las negociaciones que hubieren sido prohibidas por escrito en el respectivo contrato por el empleador.

Ahora, en el evento de no estar escrituradas, se encontrasen indeterminadas o difusas tanto sus funciones como obligaciones, su interpretación deberá ser en contra del empleador por aplicación de los artículos 1563, 1564 y 1566 del Código Civil, dejando por tanto sin sustento el ejercicio del poder disciplinario fundado en la ejecución de negociaciones incompatibles.

De otro modo, se generará una imprecisión adicional a la vaguedad de esta causal que beneficia a quien detenta una posición de superioridad, máxime si es la propia ley laboral que obliga la escrituración y claridad del contenido obligacional y funciones de la prestación laboral, ${ }^{76}$ siendo exigible por los mismos fundamentos claridad en el seno del régimen obligacional y sancionatorio.

De la misma forma, a nuestro juicio, no basta para ascender la conducta como falta disciplinaria extintiva que se establezca una prohibición de actuación en el reglamento interno, por cuanto "las infracciones a los reglamentos internos solo están sancionadas con multas" y, "según los principios generales del derecho, para incorporar nuevas cláusulas a un

\footnotetext{
${ }^{75}$ Así se ha sostenido por la Corte Suprema, de quien tomamos su razonamiento. Véase Corte Suprema, 28 de diciembre de 1995, Rol No 4814-1995, citada por CAJAS, cit. (n. 24).

${ }^{76}$ Como se desprende de una interpretación armónica y teleológica de los artículos 9, 10 y 154 del Código del Trabajo.
} 
contrato se requiere el consentimiento de ambas partes", ${ }^{77}{ }^{78}$ más aún si expresamente la norma se reconduce al concurso de voluntades y no a una fuente autónoma de integración.

\section{4) La ponderación de gravedad}

\section{a) La estructura y naturaleza del ilícito: punto de partida}

En cuanto a su naturaleza, en principio este ilícito debería ser calificado como de actividad y no de resultado, ya que el tipo normativo desde una perspectiva clásica de la estructura de los ilícitos penales- solo exige la conducta del autor para su realización, sin necesidad de un hecho separado de la misma. ${ }^{79}$ Normativamente, al igual que otros ordenamientos jurídicos, "se omite referencia a la lesividad de la actividad concurrente como elemento integrante del incumplimiento laboral". ${ }^{80}$

En este caso, la realización del tipo coincide con el último acto de la acción y, por tanto, no se produce un resultado separable de ella. ${ }^{81}$ Así, no sería correcto sostener la exigencia de un perjuicio como elemento configurante. Cosa distinta, como observaremos, es la centralidad que juega en la determinación de la gravedad de la conducta y la proporcionalidad de la sanción.

b) La proporcionalidad y los elementos valorativos: El daño y su importancia en la calificación del ilícito.

La proporcionalidad, como límite general del ejercicio del poder disciplinario, se expresa en sus dos vertientes: gradualidad de la sanción y control de mérito. ${ }^{82}$ En este esquema, dos situaciones merecen especial consideración: el perjuicio económico y la afectación del funcionamiento

\footnotetext{
${ }^{77}$ Vivanco, cit. (n. 31), pp. 67 y 68.

${ }^{78}$ En el mismo sentido, véase Corte de Apelaciones de Valdivia, 23 de diciembre de 2013, Rol No 129-2015.

${ }^{79}$ Modolell, Juan, "El tipo objetivo en los delitos de mera actividad", Política Criminal, 2016, № 11, p. 369.

${ }^{80}$ Aguilera, cit. (n. 32), p. 83.

${ }^{81}$ Roxin, Claus, Derecho Penal. Parte General, Thompson Civitas, Madrid, 1997, T.I, p. 328.

${ }^{82}$ LuJAN, José, "Algunas reflexiones sobre el principio de proporcionalidad en la calificación del despido", en: Gárate, F. (coordinador), Cuestiones actuales sobre el despido disciplinario: Estudios ofrecidos al profesor Manuel Alonso Olea, con motivo de su investidura como doctor "honoris causa" por la Universidad de Santiago de Compostela, Santiago de Compostela, 1997, p. 27. Para un mayor desarrollo, véase Luque, Manuel, Los límites jurídicos de los poderes empresariales en la relación laboral, Bosch, Barcelona, 1999, pp. 619 y ss; TerRadillos, Edurne, El poder disciplinario empresarial. Principios y garantías, Tirant lo Blanch, Valencia, 2004, pp. 45 y ss.
} 
de la empresa.

Con respecto al perjuicio económico, como indicamos, nuestro ordenamiento jurídico omite referencia a la lesividad de la actividad concurrente como elemento integrante de su tipo.

No obstante la claridad de lo anterior, la doctrina ha sido contradictoria. Por una parte, ha exigido un efecto dañoso como consecuencia del actuar del trabajador en el sentido de que, para prefigurar una competencia efectivamente atentatoria a los intereses empresariales, es requisito que la conducta provoque un serio perjuicio al empresario. ${ }^{83}$

Dicho esto, a reglón seguido, se matiza dicha exigencia: el perjuicio puede asumir distintas formas más allá de lo material o pecuniario. De igual forma tampoco se exige que se haya consumado, bastando con que potencialmente exista, por lo que bastará su potencialidad sin que sea efectivo ni real. ${ }^{84}$

En esta misma línea y por efecto de esta matización, con bastante laxitud se ha calificado este ilícito como de peligrosidad, lo que extiende desmesuradamente su alcance. ${ }^{85}$ Por lo mismo, la sola preparación de la concurrencia es sancionable con el despido, ${ }^{86}$ bastando la "plasmación real de la iniciativa", 87 justificándose la sanción extintiva por la posibilidad de existencia de peligro sin que la conducta se materialice. ${ }^{88}$

Por lo mismo, se sostiene que se "prohíbe así una situación de riesgo objetivo (peligro concreto) y la posibilidad de ocasionar un perjuicio potencial a los intereses competitivos del empleador", ${ }^{89}$ pues la esencia de este ilícito está en sancionar el quebranto de la buena fe y lealtad debida. ${ }^{90}$

No consideramos que lo anterior sea correcto. En primer lugar,

\footnotetext{
${ }^{83}$ IrURETA, cit. (n. 9), p. 65. En la jurisprudencia, véase Corte de Apelaciones de Valparaíso, 10 de marzo de 2016, Rol No 16-2016; Juzgado de Letras del Trabajo de Puente Alto, 31 de agosto de 2015, Rol N ${ }^{\circ}$ O-86-2015.

${ }^{84}$ IRURETA, cit. (n. 9), pp. 65 y ss. En la jurisprudencia, refiriéndose a la eventualidad del perjuicio, véase Corte de Apelaciones de San Miguel, 9 de noviembre de 2015, Rol № 308-2015. Similares observaciones se plantean en el ordenamiento jurídico español. Sobre el punto Aguilera, cit. (n. 32), p. 84 y OrtegA, cit. (n.13), pp. 227 y ss.

${ }^{85}$ IrURETA, cit. (n. 9), p. 43.

${ }^{86}$ Gómez, Francisco, "Las Causas Disciplinarias", en: Sempere, A.; Martín, R., (eds.), El Despido, Thomson Reuters, Aranzadi, 2009, p. 260.

${ }^{87}$ Sempere, cit. (n. 45), p. 40.

${ }^{88}$ Irureta, cit. (n. 9), p. 66; Gómez, cit. (n. 86), pp. 261 y ss.; Sempere, cit. (n. 45).

${ }^{89}$ Nogueira, cit. (n. 10), p. 204.

${ }^{90}$ Así se reseña por la jurisprudencia comparada AguilerA, cit. (n. 32), pp. 84 y ss.
} 
como indicamos, la prohibición de negociaciones dentro del giro del empleador constituye una hipótesis de concurrencia relativa y no una forma de competencia desleal. Esta calificación modifica los estándares de interpretación en la medida que ante la noción de competencia desleal se amplía el margen discrecional en la predeterminación de comportamientos sancionables, lo que se produce por efecto de la tendencia empresarial de calificar simples actos de competencia como ilegales. ${ }^{91}$

De esta forma, se impone la necesaria limitación de la centralidad que ha de tener la autonomía de la voluntad en la definición de los núcleos extintivos, los que se restringen con una técnica prohibitiva dada por la heteronorma y que solamente puede ser coherente reconociendo el ilícito laboral como una forma de concurrencia relativa. Así, solamente podemos reconducirnos estrictamente al tipo y no a un plano subjetivo que, en cierta medida, justifica la calificación de peligrosidad abstracta o la sanción de hipótesis imperfectas, frustradas o preparatorias de la ejecución de la negociación dentro del giro del empleador.

En segundo lugar, desde la perspectiva de la dogmática penal — de donde emana esta caracterización-, nos parece extremo calificar el ilícito del artículo 160 número 2 del Código del Trabajo como uno de peligrosidad abstracta. Desde un punto de vista teórico, estos ilícitos son aquellos en que se castiga una conducta típicamente peligrosa, sin que en el caso concreto deba producirse un resultado de puesta en peligro. Así, la punibilidad de la sanción deriva de la gravedad de la conducta en atención al bien jurídico protegido que justifica el marco sancionatorio. ${ }^{92}$ En tal caso, pese a las distintas teorías para justificar estos ilícitos, existe coincidencia en que pretenden proteger la vida e integridad de las personas puestas en peligro abstractamente, aunque ello no se exprese directamente en el tipo. ${ }^{93}$

Dicho esto, en el caso de la prohibición de negociaciones ejecutadas por el trabajador dentro del giro de la empresa, no nos encontramos ante una situación de peligrosidad o gravedad que justifique su caracterización dentro de las líneas de estos ilícitos. Incluso, es más, desde la lógica de la competencia desleal, el fundamento está en un conflicto entre particulares: la pérdida de confianza, la infracción a la buena fe y la violación al deber de lealtad y cuidado, los que claramente no tienen una entidad ponderativa que

\footnotetext{
${ }^{91}$ Baylos, cit. (n. 10), p. 10.

${ }^{92}$ Roxin, cit. (n. 81), p. 407.

${ }^{93}$ Roxin, cit. (n. 81), p. 408.
} 
justifique su calificación como de peligrosidad abstracta.

Adicionalmente, se debe recordar que en materia laboral no existe normativamente una distinción del iter sancionable que justifique la punibilidad de conductas laborales en etapas anteriores a la consumación, como la tentativa y frustración. En esta línea, el tipo laboral solo sanciona la conducta consumada al exigir que el trabajador "ejecute" las negociaciones, por lo que no parece razonable, desde la técnica de la tipicidad, sancionar hipótesis de actos preparatorios de la ejecución con la extinción del contrato.

Así, desde la racionalidad del principio de proporcionalidad como límite al ejercicio del poder disciplinario, no es posible sancionar con la misma gravedad una conducta consumada que aquella que este frustrada o tentada, o incluso, que ha comenzado su ejecución sin estar satisfecho el núcleo del tipo laboral. Lo mismo ocurre frente al perjuicio real y abstracto, o si quiere, efectivo o potencial.

A modo de conclusión, creemos que debe entenderse el daño como una idea intrínseca a la noción de competencia, estando, por lo tanto, en principio permitido. Por lo mismo, la simple concurrencia no es suficiente, debiendo existir un perjuicio efectivo. La negociación prohibida debe estar cualificada por un rasgo distintivo, adicional, que justifique su calificación como ilícito que, en tal caso, vendrá dado por la lesividad que solamente puede ser de un daño concreto, descartando hipótesis imperfectas, tentativas o frustradas.

c) La proporcionalidad y los elementos valorativos: El funcionamiento de la empresa y el estándar de proporcionalidad.

En el debate anterior, y de manera más concreta, igual importancia tiene la idea de afectación del funcionamiento de la empresa la que, a nuestro entender, es la noción que pondera la gravedad de la conducta.

A nuestro entender, este elemento solo podrá ser dado en la medida en que la actividad de concurrencia, razonable y objetivamente, ponga al trabajador en una situación de conflicto real con los intereses competitivos del empleador. Esto, debido a que la prohibición de competencia "no puede proyectarse indiscriminadamente sobre cualquier prestación de trabajo", siendo únicamente justificable para aquellas prestaciones que sean susceptibles, objetivamente, de ocasionar un daño a los intereses competitivos del empleador. ${ }^{94}$

${ }^{94}$ Sobre el punto, véase Nogueira, cit. (n. 10), p. 239 y Ortega, cit. (n.13), pp. 222 y ss. 
Desde un punto de vista de la creación del riesgo concreto y objetivo de afectación de intereses empresariales, el factor indicativo de relevancia será el de la ejecución de la tarea principal en relación con la tarea secundaria ejecutada por el trabajador en concurrencia con su empleador.

Esto se debe a que no todo trabajo o actividad que desempeña un trabajador en una empresa de la competencia o por cuenta propia genera automáticamente un riesgo de afectación de los intereses competitivos de su empleador. ${ }^{95}$ De esta forma, solo existirá cuando se presente una correspondencia material entre la actividad principal desarrollada por el trabajador y las secundarias ejecutadas en el mercado concurrencial, debiendo existir una identidad sustantiva entre las funciones desempeñadas en virtud de su contrato de trabajo y las desplegadas en favor de la competencia, las que deberán ser similares en una dimensión material, espacial y territorial. ${ }^{96}$

No obstante, adicionalmente, creemos que será necesario que la actividad principal, en relación con la secundaria, sea determinante dentro del desarrollo del giro de la actividad empresarial, en la medida que la ejecución de esta sea por sus características técnicas o estratégicas, la constituyan en relevante, excluyendo, por tanto, aquellas tareas inferiores o menores dentro del esquema de organizacional.

En este caso, de no observarse los criterios ponderativos anteriores, el despido en cuanto medida extintiva no supera los estándares de idoneidad, necesidad y proporcionalidad, por cuanto no existiría una concurrencia apta para afectar los intereses empresariales, ya que no hay una tarea relevante o un perjuicio real y efectivo que nos permita entender que estamos ante un atentado a la libre competencia, sino más bien ante una hipótesis válida de ejercicio de la garantía de libertad de trabajo en su vertiente de pluriempleo, siendo una consideración en el orden ponderativo. ${ }^{97}$

\footnotetext{
${ }^{95}$ En este sentido, véase $1^{\circ}$ Juzgado de Letras del Trabajo de Santiago, 31 de julio de 2014, Rol No T-165-2014. En un sentido contrario, $1^{\circ}$ Juzgado de Letras del Trabajo de Santiago, 6 de enero de 2014, Rol No O-3761-2013.

${ }^{96}$ Nogueira, cit. (n. 10), p. 252 y Ortega, cit. (n.13), pp. 222 y ss.

${ }^{97}$ En esta línea, se ha resuelto expresamente que la "protección de la estabilidad relativa en el empleo", en esta causal, igualmente condiciona el despido como "la última alternativa que tome el empleador, una vez agotado otros recursos como una amonestación o sanción, es decir, debe ser aplicada la causal invocada por la demandada única y exclusivamente como última ratio". Véase Corte de Apelaciones de Valdivia, 23 de diciembre de 2016, Rol № 132-2016, (sentencia de reemplazo).
} 


\section{CONCLUSIÓN}

Al igual que el resto de las causales de despido disciplinario del Código del Trabajo, el núcleo de la conducta prohibida se encuentra definido por conceptos jurídicos de difícil delimitación.

En su consideración, ha existido una excesiva visión de tutela empresarial que ha debilitado los contornos y alcances habilitantes de esta causal de despido, permitiendo su reconducción y extensión a supuestos de hecho que, desde una lectura finalista del derecho del trabajo, como también de eficacia de los derechos fundamentales, sería contraria a las reglas de tipicidad, como también, vulneradora de la libertad de trabajo y su protección.

En este esquema, creemos que una visión garantista de despido como expresión autotutelar y de poder privado nos permite definir este ilícito laboral como una hipótesis de no concurrencia relativa o parcial que, en su estructura tipológica, responde a un ilícito de mera actividad en la que solamente se sanciona la conducta consumada excluyendo actos preparatorios de ejecución.

En cuanto a la conducta prohibida, se trata de un non facere que viene configurado por la abstención de ejecución de actividades mercantiles o civiles por cuenta propia, autónomas o de carácter asociativo, que se encuentren dentro del giro del empleador y no así actividades laborales o subordinadas.

Para este efecto, su determinación no solo será dada por el sustrato fáctico de la actividad prohibida, sino también por las normas comerciales que la regulan, estando impedida la prohibición de actividades que estén fuera del giro de la empresa y que estén expresamente prohibidas por escrito.

En cuanto a la lesividad, si bien no forma parte de la estructura del tipo, no cualquier concurrencia sirve de fundamento para justificar la extinción del contrato de trabajo. Esto deriva desde el principio de proporcionalidad como límite al ejercicio del poder disciplinario, estando intrínsecamente vinculado con la noción de competencia. Por lo mismo, la concurrencia debe estar cualificada por un rasgo distintivo, adicional, que justifique su calificación como ilícito, el que en este caso vendrá dado por el perjuicio económico a la empresa como elemento ponderativo de gravedad, que responde a estándares de objetividad, reales y concretos, vinculados a la idoneidad, necesidad y proporcionalidad como juicios de valor. 


\section{BIBLIOGRAFÍA}

\section{a) Doctrina}

Aguilera, Raquel, Las causas de Despido Disciplinario y su valoración por la jurisprudencial, Thomson Reuters Aranzadi, Madrid, 1997.

BAYLos, Antonio, "La prohibición de concurrencia desleal: Notas sobre la evolución legal y jurisprudencial", Temas Laborales, 1986, № 8 .

CAJAS, Alejandra, "La prohibición de competencia desleal en el contrato de trabajo", Actas II Congreso Nacional Estudiantil de Derecho del Trabajo, 2012.

CastiñeIra, Jaime, Prohibición de competencia y contrato de trabajo, Ministerio del Trabajo y Seguridad Social, Madrid, 1977.

Courtis, Christian, "El juego de los juristas. Ensayo de caracterización de la investigación dogmática", en: Courtis, C., Observar la ley. Ensayos sobre metodología de la investigación jurídica, Editorial Trotta, Madrid, 2006.

Domínguez, Álvaro, "Análisis crítico al Derecho del Trabajo: entre el paternalismo y la emancipación”, Ius Novum, 2014.

Etcheberry, Francoise, Derecho Individual del Trabajo, Legal Publishing, Santiago, 2011. 1991.

Fernández, María, El poder disciplinario en la empresa, Civitas, Madrid,

Gaete, Alfredo, Tratado de Derecho del Trabajo y Seguridad Social, Editorial Jurídica, Santiago, 1967, T.I.

Gamonal, Sergio; Guidi, Catherina, Manual del Contrato de Trabajo, Legal Publishing, Santiago, 2011.

GiL y GiL, José Luis, Autotutela privada y poder disciplinario en la empresa, Centro de Publicaciones del Ministerio de Justicia, Madrid, 1993.

Gómez, Francisco, "Las Causas Disciplinarias", en: Sempere, A.; Martín, R., (eds.), El Despido, Thomson Reuters, Aranzadi, 2009.

IruRetA, Pedro, "La prohibición de competencia y buena fe contractual", Estudios Laborales, 2007, V.I.

LANATA, Gabriela, Contrato Individual de Trabajo, Legal Publishing, Santiago, 2010.

Lizama Portal, Luis; Lizama CAstro, Diego, Manual de Derecho Individual del Trabajo, DER, Santiago, 2019.

Lizama, Luis, Derecho del Trabajo, Editorial Lexis Nexis, Santiago, 2003.

LuJAN, José, "Algunas reflexiones sobre el principio de proporcionalidad en la calificación del despido", en: Gárate, F. (coordinador), Cuestiones actuales sobre el despido disciplinario: Estudios ofrecidos al profesor Manuel Alonso Olea, con motivo de su investidura como doctor "honoris causa" por la Universidad de Santiago de Compostela, Santiago de Compostela, 1997.

LuQue, Manuel, Los límites jurídicos de los poderes empresariales en la 
relación laboral, Bosch, Barcelona, 1999.

Macchiavelo, Guido, Derecho del Trabajo, Fondo de Cultura Económica, México, 1986, T. I.

Melis, Cristián; SÁez, Felipe, El Contrato Individual de Trabajo en los Dictámenes de la Dirección del Trabajo, Legal Publishing, Santiago, 2009.

Modolell, Juan, "El tipo objetivo en los delitos de mera actividad", Política Criminal, 2016, № 11.

Nadal, Daniel, El despido en el Código del Trabajo, Lexis Nexis, Santiago, 2003.

Nevado, María José, Las restricciones a la competencia en el contrato de trabajo, Editorial Tecnos, Madrid 1998.

NogueIRA, Magdalena, La prohibición de competencia desleal en el contrato de Trabajo, Editorial Aranzadi, Pampona, 1997.

Pedrajas, Abdón, "La prohibición de concurrencia postcontractual. Estudio crítico del artículo 74 de la ley de contrato de trabajo", Revista de Trabajo, 1976, $\mathrm{N}^{\circ} 56$. 2018.

PIERry, Lucía, Derecho individual del trabajo, Ediciones Der, Santiago,

RodríGuez-PiÑEIRO, Miguel, "Límites a la competencia y contrato de trabajo", Revista de Política Social, 1977, Nº 116.

Rojas, Irene, Derecho Individual del Trabajo, Editorial Thomson Reuters, Santiago, 2015.

Roxin, Claus, Derecho Penal. Parte General, Thompson Civitas, Madrid, 1997, T.I.

SEMPERE, Antonio, "Despido disciplinario y preparación de la competencia desleal", Aranzadi Social, 1991, Nº 5.

RuIz, José, Metodología de la investigación cualitativa, Universidad de Deusto, Bilbao, 2012.

Ortega, Pompeyo, Poderes empresariales y resolución del contrato de trabajo por incumplimiento del trabajador, Comares, Granda, 2020.

SiERrA, Alfredo, "La cláusula de no competencia post-contractual en el contrato de trabajo", Ius et Praxis, 2014, N².

SuppIEJ, Giuseppe, Il rapporto di lavoro. Costituzione e svolgimento, CEDAM, 1982.

Thayer, William; Novoa, Patricio, Manual de Derecho del Trabajo, Editorial Jurídica de Chile, Santiago, 2019, T.4.

Terradillos, Edurne, El poder disciplinario empresarial. Principios y garantías, Tirant lo Blanch, Valencia, 2004.

Verd, Joan; LozAres, Carlos, Introducción a la investigación cualitativa. Fases, métodos y técnicas, Síntesis, Madrid, 2006.

Vergara, Rafael, Terminación del Contrato de Trabajo, Editorial 
Metropolitana, Santiago, 2014, T.II.

Vivanco, Manuel, El Despido Laboral, Editorial Jurídica de Chile, Santiago, 1994.

WALKer, Francisco, Derecho de las Relaciones Laborales, Editorial Universitaria, Santiago, 2003.

Walker, Francisco, Nuevas Normas. Terminación del contrato de trabajo, 1990.

\section{b) Jurisprudencia}

Corte Suprema, 16 de noviembre de 2010, Rol No 5531-2010.

Corte Suprema, 28 de mayo de 2002, Rol No 747-2002.

Corte Suprema, 28 de diciembre de 1995, Rol No 4814-1995.

Corte de Apelaciones de Concepción, 2 de julio de 2015, Rol No 100-2015.

Corte de Apelaciones de Concepción, 2 de julio de 2015, Rol No 100-2015.

Corte de Apelaciones de Puerto Montt, 13 de noviembre de 2006, Rol No 156-2006.

Corte de Apelaciones de Santiago, 21 de octubre de 2004, Gaceta Jurídica, $\mathrm{N}^{\mathrm{o}} 292$, octubre de 2014.

Corte de Apelaciones de Santiago, 31 de enero de 1995, Rol No 336-1994. 2015.

Corte de Apelaciones de Valdivia, 23 de diciembre de 2013, Rol No 129 -

Corte de Apelaciones de Valdivia, 23 de diciembre de 2016, Rol N ${ }^{\circ} 132-$ 2016 (sentencia de reemplazo).

Juzgado de Letras del Trabajo de Chillán, 15 de enero de 2016, Rol No O-272-2015.

Corte de Apelaciones de Valparaíso, 10 de marzo de 2016, Rol N 16-2016. 2015.

Corte de Apelaciones de San Miguel, 9 de noviembre de 2015, Rol No 308-

Juzgado de Letras del Trabajo de Puente Alto, 31 de agosto de 2015, Rol N O-86-2015.

$1^{\circ}$ Juzgado de Letras del Trabajo de Santiago, 6 de noviembre de 2013, Rol $\mathrm{N}^{\mathrm{o}} \mathrm{O}-3016-2013$.

$2^{\circ}$ Juzgado de Letras del Trabajo de Santiago, 2 de febrero de 2013, Rol N ${ }^{\circ}$ O-2792-2012.

$2^{\circ}$ Juzgado de Letras del Trabajo de Santiago, 6 de abril de 2015, Rol N ${ }^{\circ}$ O-4581-2014.

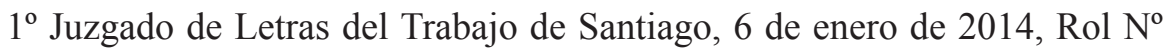
O-3761-2013.

$2^{\circ}$ Juzgado de Letras del Trabajo de Santiago, 3 de julio de 2012, Rol No O-1073-2012.

Juzgado de Letras del Trabajo de Iquique, 29 de agosto de 2012, Rol No 
O-49-2012.

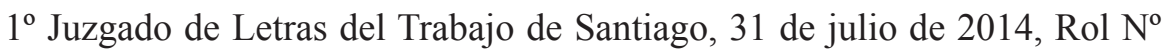
T-165-2014.

$2^{\circ}$ Juzgado de Letras del Trabajo de Santiago, 30 de julio de 2011, Rol No O-602-2011.

$2^{\circ}$ juzgado de Letras del Trabajo de Santiago, 8 de enero de 2015 , Rol No T-303-2014.

$1^{\circ}$ Juzgado de Letras del Trabajo de Santiago, 23 de diciembre de 2011, Rol $\mathrm{N}^{\mathrm{o}} \mathrm{O}-3002-2011$.

$2^{\circ}$ Juzgado de Letras del Trabajo de San Fernando, 16 de agosto de 2012, Rol No O-18-2012.

Juzgado de Letras del Trabajo de Iquique, 25 de junio de 2012, Rol No O-632012.

Juzgado de Letras del Trabajo de Valparaíso, 6 de $\mathrm{m}$ ayo de 2010, Rol No O-731-2009. 